\title{
Verification of Practical Applicability of Cable Wiring for PLG Ground Coils to Maglev Systems
}

\author{
Noriyuki TAKAHASHI \\ Senior Researcher, \\ Masao SUZUKI \\ Senior Researcher, Laboratory Head, \\ Electromagnetic Guideway Technology Laboratory, Maglev Systems Technology Division \\ PLG ground coils offering three functions, namely propulsion, levitation and guidance, \\ used on superconducting maglev systems have been developed for construction by RTRI with \\ a view to reducing cost by cutting the required overall number of coils. PLG coils however \\ require guidance circuits made up of high voltage cables connecting facing coils. This cable \\ installation is complicated and intricate. A model guideway was built therefore in order to \\ investigate ways to reduce wiring. Tests were then performed with the optimal wiring solu- \\ tions discovered, on a full size model. Results helped determine the suitable section size for \\ duct lines, the required length of connection cables, the appropriate wiring procedures and \\ an effective wiring layout. The outcome of these tests indicate that there are prospects for a \\ problem-free approach to PLG coil cable wiring.
}

Keywords: superconducting maglev system, ground coil, cable, PLG coil, construction verification

\section{Introduction}

Ground coils employed along magnetic levitation train lines are not only numerous but also exposed for long periods of time to outside weather conditions. Ground coils must therefore developed with the best possible functionality and reliability, while at the same time, calls are being made to reduce production and installation costs.

PLG coils (combining the propulsion, levitation and guidance functions) have been developed at RTRI with a view to achieving savings by cutting the required number of coils and simplifying the installation process. These coils however require a high voltage connection null-flux cable (as illustrated in Fig.1) which renders the wiring process more complex. As a result there is a need for tests to verify the practical applicability of this approach before examining the actual cable laying process.

This type of PLG coil has been applied to and tested on the Yamanashi Maglev Test Line a short period (Fig.2). Nonetheless certain conditions of these tests mean that results cannot be used to evaluate applicability of this method, such as: (1) The cables were added to an existing guideway, so the conditions were exceptional; (2) Only four coils were installed, which does not correspond to continuous installation conditions which would be expected on an operating line.

For this reason, before proceeding to a full-scale evaluation of this method's applicability, a number of parameters need to be checked, such as length of cable and order in which cables should be laid.

Consequently, a model guideway was built in order to examine cable layout before actually constructing a fullscale model guideway for performing feasibility tests.

This paper explains on the results of the work by scaled-down model study and the confirmation of cable routing characteristics on the model guideway.

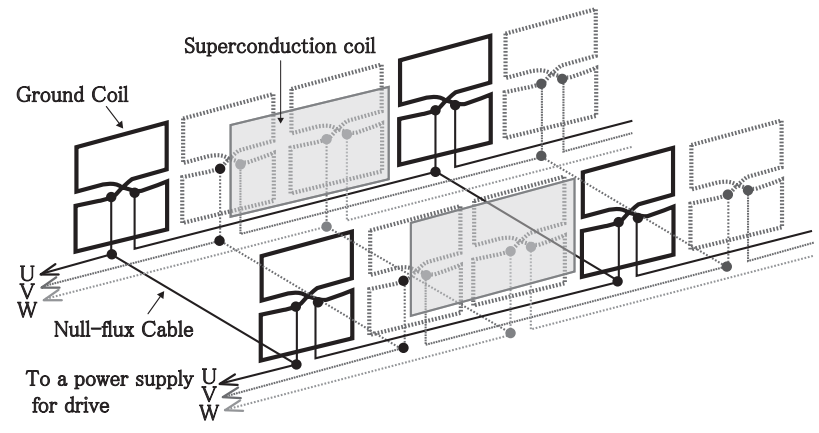

Fig. 1 Cable layout for the PLG method

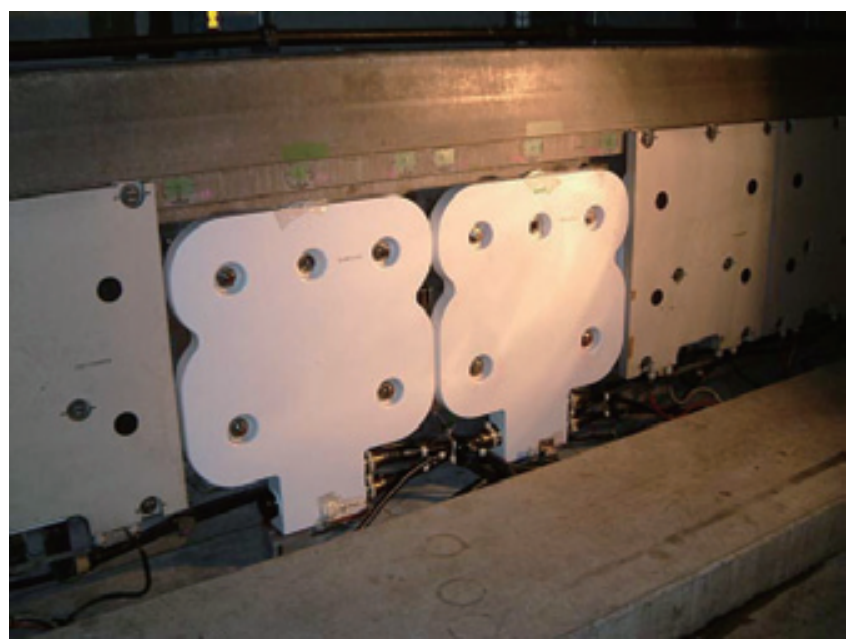

Fig. 2 PLG ground coils laid for evaluation tests (Yamanashi Maglev Test Line) 


\section{Prior confirmation through scaled-down modeling}

\subsection{Scaled-down model study}

\subsubsection{Examination of main body parts}

The scope and number of configurations which can be verified on a full-scale model are restricted. Therefore, it is more effective to carry out preliminary investigations using a small scale model to determine the required length of cable and laying procedure, before checking the effectiveness of the evaluation process. The model it was made to scale of 1/10 and long enough to house 12 coils. The floor of the model representing the roadbed and the duct line exit wall, were made from transparent material in appropriate places in order to be able to investigate diagonal wiring. A hole of $\varphi 15 \mathrm{~mm}$ was opened every $45 \mathrm{~mm}$ (half ground coil distance) to form the duct line entrances. The beam-type method was used for the sidewall, where the sidewall is fixed on pedestals. The model was designed so that 6 coils were fixed to each beam, dividing them into two groups, in order to be able to examine cable layout in between pedestals. Ground coils are attached to the sidewall with a magnet at this model. The sidewall was designed to make it possible to fix the magnets in predetermined positions. The ground coils were designed to be reversible making it possible to investigate the ground coil terminals in reversed configuration, and also making it possible to examine a greater number of possible layouts. The whole model is shown in Fig. 3.

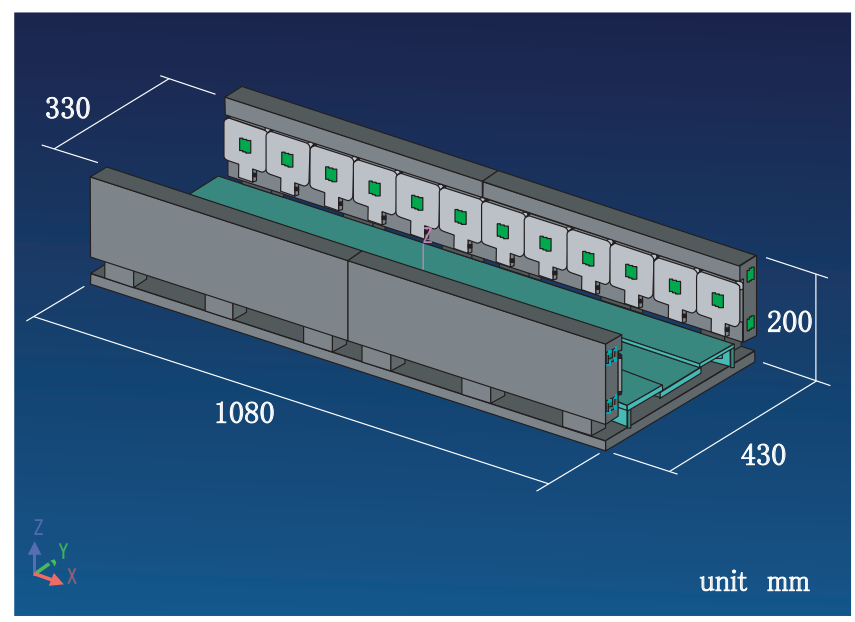

Fig. 3 Bird's-eye view of the model guideway

\subsubsection{Examination of the cable elements}

Cable for the tests had to be flexible and pliant enough so they would not break easily. The wire diameter also had to match the scale of the model, and had to be easy to use. The wire connectors had to offer simple connectivity while being firm enough to prevent unwanted disconnections. In order to meet these requirements, it was decided to use connector pins with $1.25 \mathrm{~mm}^{2}$ diameter LFV cable. Various wire and connector pin colors are available, so a different color was used for each phase, facilitating the examination and evaluation.

\subsection{Scaled-down model investigations}

The following investigations were carried out on the model described above:

(1) Estimation of the cable length for the propulsion coils on one side of the guideway

This follows the most standard form of connection, which is to link up matching phases. As illustrated by Fig.4, the cable is laid straight to estimate its length after having been laid out in the model. The estimate length of the cable in this instance was $300 \mathrm{~mm}$.

(2) Estimation of the null-flux cable length

The total length of the straightened cable was measured after the required length was laid out in the model, as shown in Fig. 5. Given that this cable is subject to constriction such as at the entrance to the duct line, tests were carried out using a jig, in order to reduce any unnecessary bending. Based on this examination, the null-flux cable length was estimated to around $600 \mathrm{~mm}$.

(3) Study of cable routing around the lower part of the ground coil

The layout for the two cables described above in (1) and (2) is considerably complex. In order to imagine what cable installation would be like under real conditions, veri-

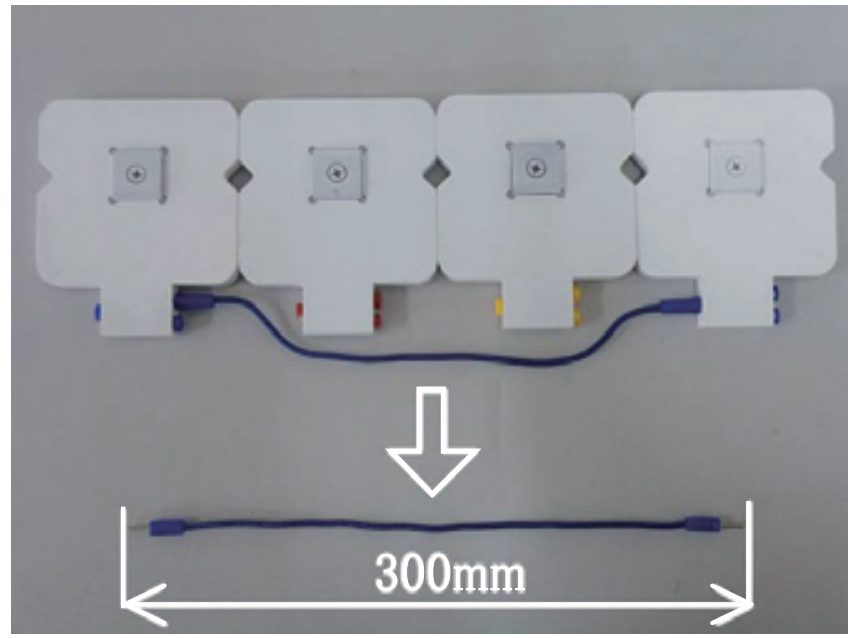

Fig. 4 Determination of connection cable length

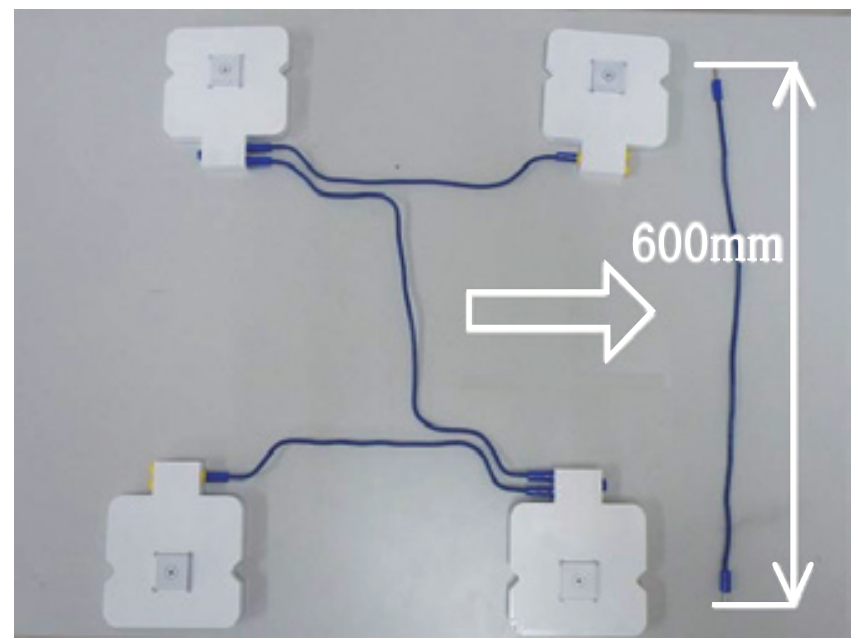

Fig. 5 Determination of null-flux cable length 
fications and investigations were carried out to examine the relationship between the cables (such as whether one should be on top or behind, where they should cross, etc.). In the case of a beam structure, work on cable (1) was carried out first, followed by the laying out of cable (2). Wiring was done to reflect this order. The wiring order following this pattern is shown in Fig. 6.

(4) Examination of cable routing using diagonal duct lines

A method for shortening the required length of nullflex cable is shown in Fig. 7(b) by putting duct lines diagonally (Normal connection is shown in Fig. 7(a)). This method offers the extra advantage of reducing the bending
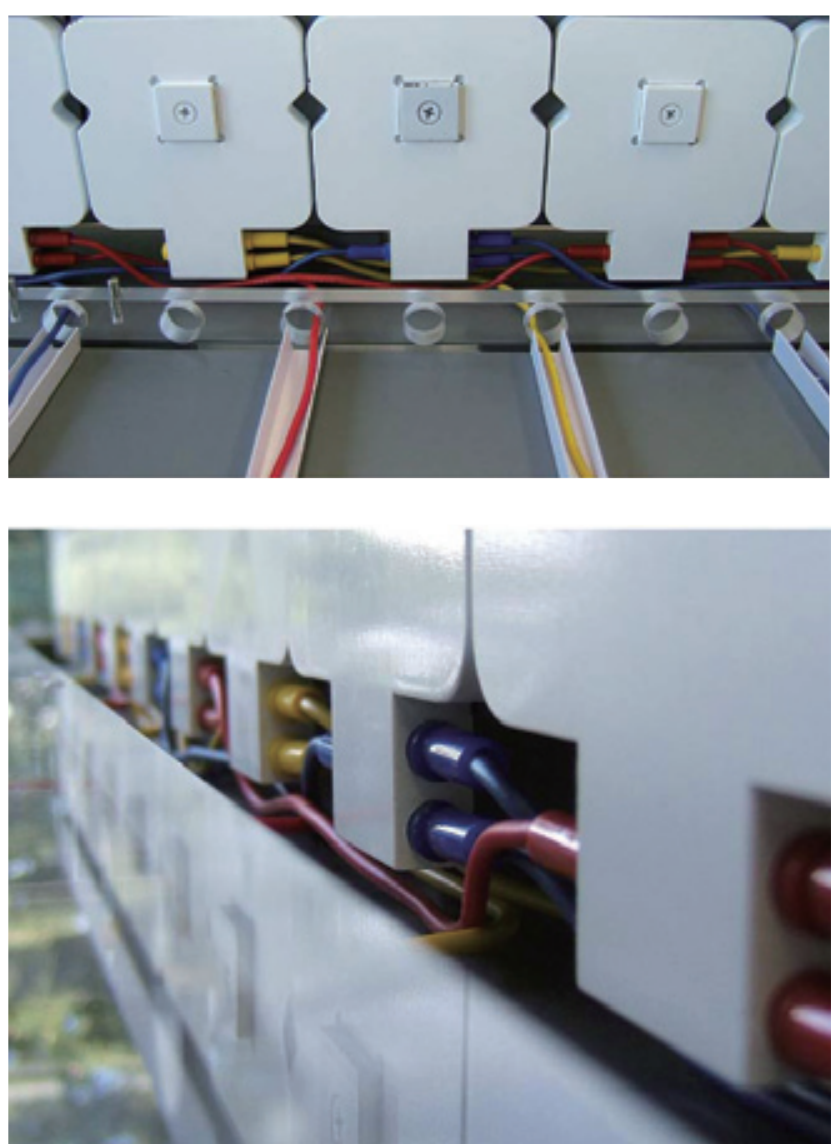

Fig. 6 Examination of connection cable length
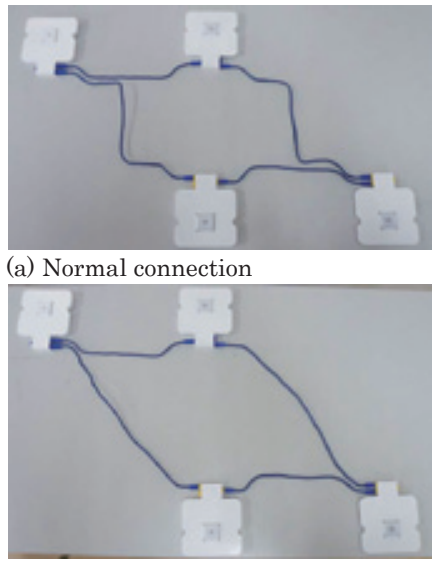

(b) Diagonal connection

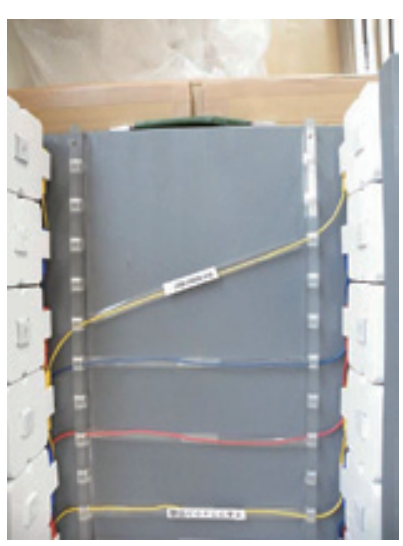

(c) Comparison

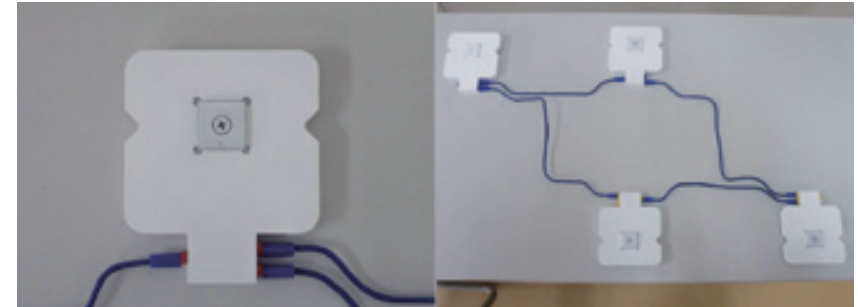

(a) Normal

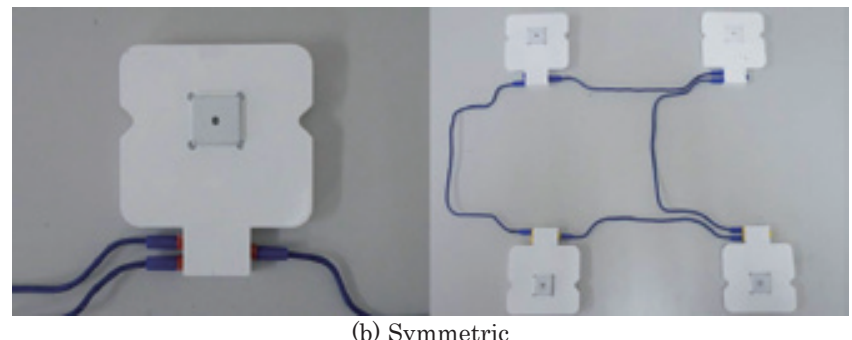

Fig. 8 Ground coil in symmetric connection and examination of connections

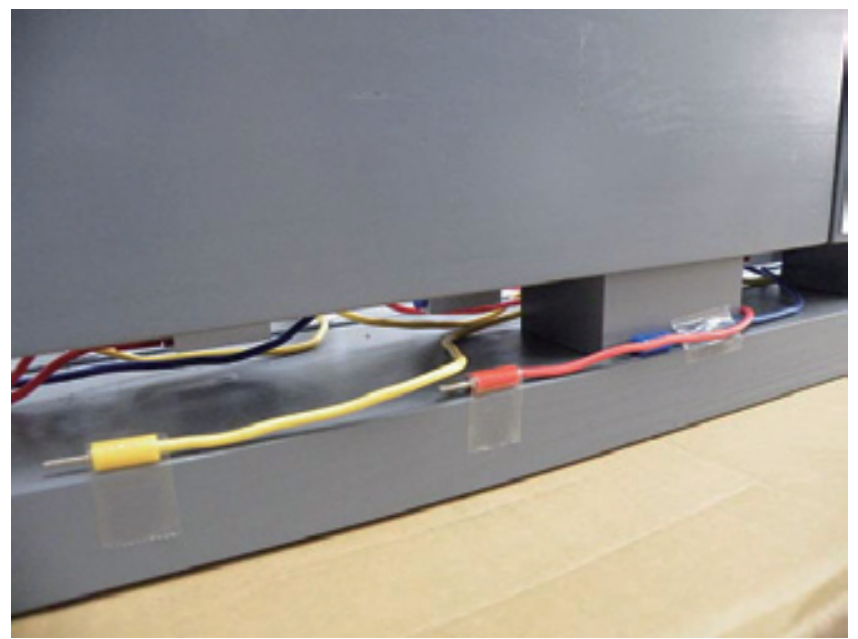

Fig. 9 Examination of cables drawn outside the guidway

radius of the cable at the duct line exit. Figure 7(c) is a picture taken of this approach applied to the model.

(5) Examination of cable routing with symmetric ground coils

Figure 8(a) shows the cable layout using the same type of coil. When the coil terminals are aligned on both sides of the road bed opposite each other as shown in Fig. 8(b), the null-flux cable circuit becomes more compact. A picture was then taken of this circuit when applied to the model.

(6) Examination of end sections

Unlike the normal pattern, wiring of terminal end sections requires cables to be passed outside the guideway, and routing and duct lines must therefore be examined separately in these cases. Figure 9 shows an example of one of the possible layouts examined which leaves the guideway.

Fig. 7 Examination into diagonal wiring 


\section{Production of the full size model guide way}

A full size model guideway was built using the side wall beam type method, fixed to pedestals. The distances between coils, width of the guideway, location of coils etc., were based on actual values. A picture of the experimental full size guideway is shown in Fig. 10. The model was $8 \mathrm{~m}$ long, by a full width of $4 \mathrm{~m}$. The roadbed was made of steel reinforced concrete, however, given that this mock-up was only for simulation, real train reaction force was not taken into account and ordinary steel (as opposed to low-magnetic steel) was used for the rebar. The roadbed itself was flat with a smooth surface. Corrugated FEP tubes were embedded to serve as null-flux conduits at the same $0.9 \mathrm{~m}$ intervals as the ground coils. Three types of duct opening illustrated in Fig. 11 were examined, namely: type (A) in the form of a bell mouth, and two trumpet-shaped outlets, one small - B and the other larger - C. Diagrams of openings $\mathrm{B}$ and $\mathrm{C}$ are shown in Fig. 12. Ground coils were put in place six on each side.

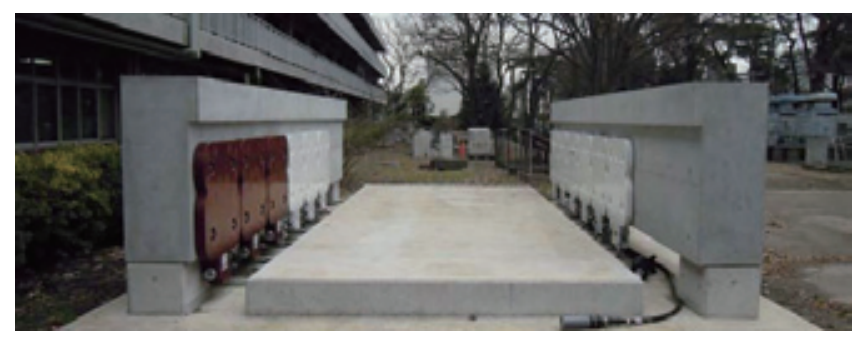

Fig. 10 Full size guideway for construction for practical evaluation

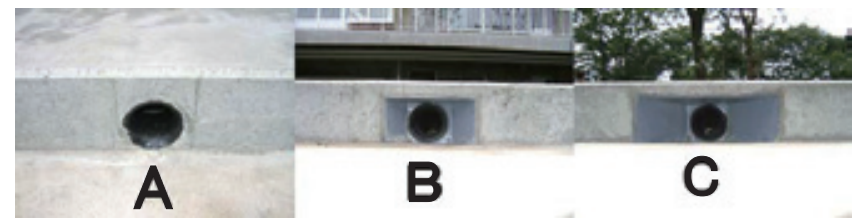

Fig. 11 Three types of duct opening
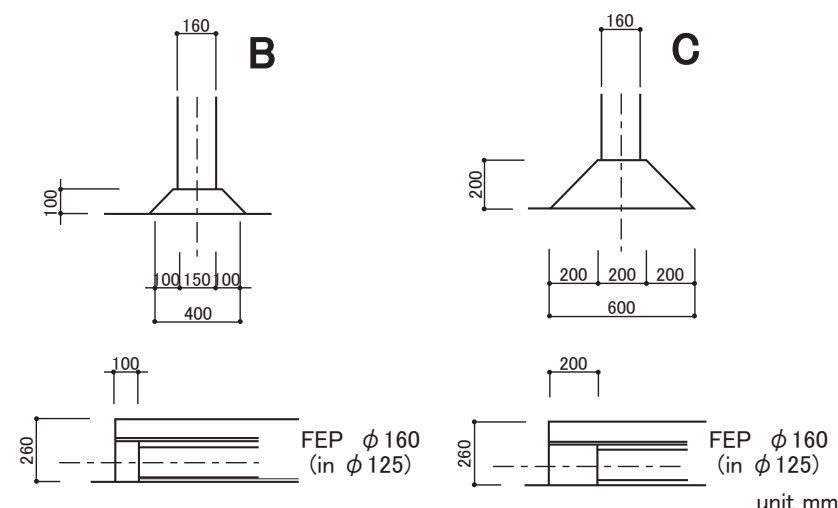

Fig. 12 Size of duct openings

\section{Confirmation of Cable routing characteristics on the model guide way}

\subsection{Study of the cable length}

The cables for which length has to be determined can be broadly divided into three groups: (1) Standard cross cables between phases (in the track direction, cf. Fig. 4), (2) nullflux connection cables (sleeper direction, cf. Fig. 5) and (3) other types of cable (approach cables, terminal sections, and special length cables, etc.).

At first, a long distance cable was prepared connected only to the connectors on one side. The cable was then connected to the coil of another terminal. After the position of the route to the next terminal was checked, the cable length was determined. The null-flux cables were put in place taking into account the required bending radius (minimum bending radius $360 \mathrm{~mm}$ ). The result of this process gave a standard cross cable length between phases of $2700 \mathrm{~mm}$, and a null-flux cable length of $5700 \mathrm{~mm}$.

\subsection{Confirmation of applicability of cable laying work}

An attempt was made construct a full cable layout of 15 cables, consisting of the 8 cable lengths considered in the previous section 4.1 ( 6 phase cables and 2 null-flux cables) and traditional 7 cables, in order to verify the applicability of this cable routing design. Two cable patterns were applied namely pattern A with special section border connections and pattern B with normal connections within sections.

\subsubsection{Pattern A}

Cable connections for pattern A are shown in Fig.13. Firstly, the phase cables are connected, followed by the null-flux cables. Then, given that the traditional cable lengths are not suitable, only the connector on one side is hooked up. The other side of the cable is laid out, but not

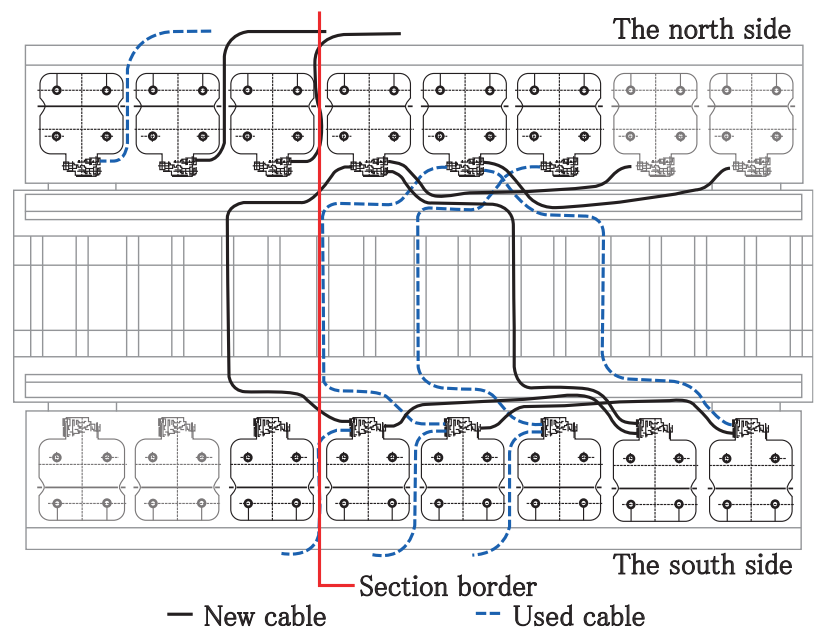

Fig. 13 Pattern 'A' circuit diagram 


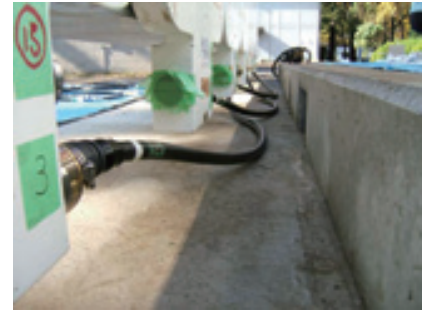

(a) Phase cables

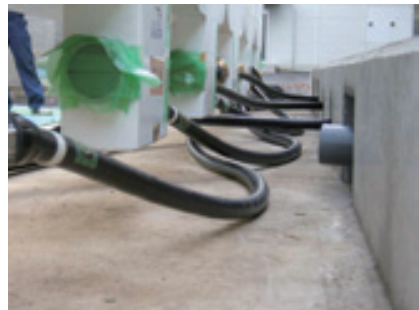

(b) Null-flux cables
Fig. 14 Picture of cable connections (pattern 'A')

connected. The phase cables were arranged as shown in Fig. 14 (a), the null-flux cables as in Fig.14 (b). The routing followed expectations, and there were no problems in making the connections.

\subsubsection{Pattern B}

Some of the cable connections from pattern A were kept in the transition to pattern $\mathrm{B}$. The null-flux cables and some other cables were pulled out in order to re-route and reconnect them. Pattern $\mathrm{B}$ cable layout is illustrated in Fig. 15.

During the actual laying work, compared to pattern A, pattern B involved more cross over points and in order to achieve the pattern, the minimum radius had to be occasionally exceeded (momentary excessive bending during laying work is not a problem).

Furthermore, in practice, phase cables are connected off-site in a yard etc., on the assumption that the null-flux cables are then connected locally. For the sake of comparison, on the south side as illustrated in Fig. 16 (b), the nullflux cables are fitted to the upper part of the connector, and the phase cable to the lower part (as shown in Fig. 16 (a) the connections are reversed in other locations). This approach proved to be make cable laying difficult and highlighted a number of points which would have to be reconsidered, such as fixed cleat locations, and fixing methods.

The north side

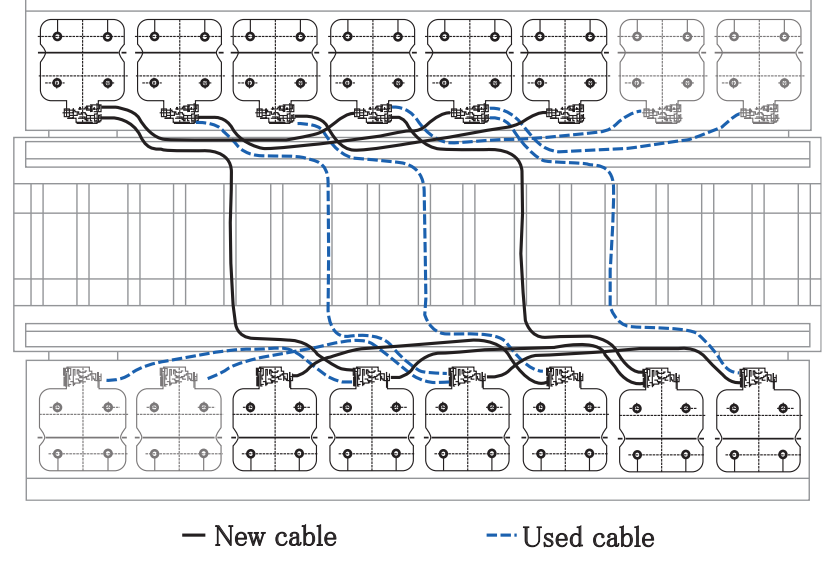

Fig. 15 Pattern 'B' circuit diagram

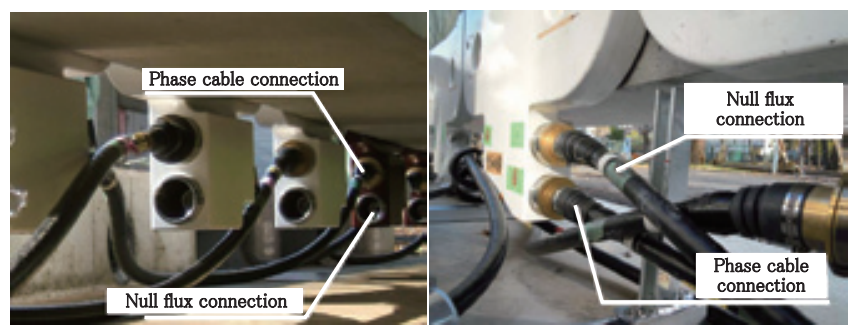

(a) Normal cables position

(b) Inverted connection

\subsection{Cable cleat fixtures}

In order to control cable vibration and reduce the load on connectors, it is vital for cables to be fixed in certain places. A number of cable cleat fastenings and fixing methods were studied for this purpose. In order to determine the cable fixing distances, the standard coil pitch of $900 \mathrm{~mm}$ at the Yamanashi maglev test line was used as a reference, though shorter distances were investigated. The point at which the cable bends at an angle of 45 degrees between the coil and the null-flux cable duct mouth was used as a basis. The cleat positions for the phase connections and the null-flux cables are shown in Fig. 17 (a) and Fig. 17 (b) respectively. Cables were held in place between the coils by vertical stands fixed to the roadbed, with metallic rings. Figure18 illustrates the cable bundling fastening ring, the individual ring cable cleat inter alia. All the methods were

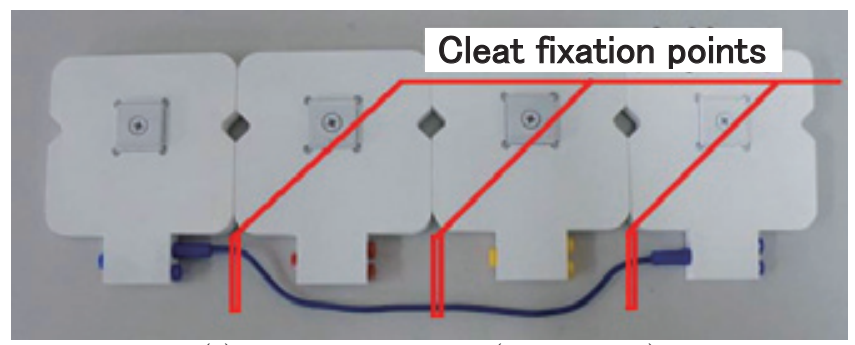

(a) Cleat fixation point (Phase cable)

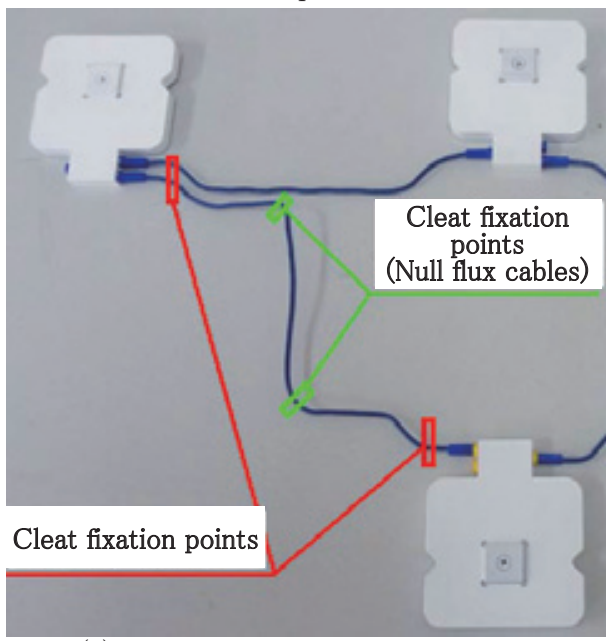

(b) Cleat position for null-flux cables

Fig. 17 Cable fixation point 


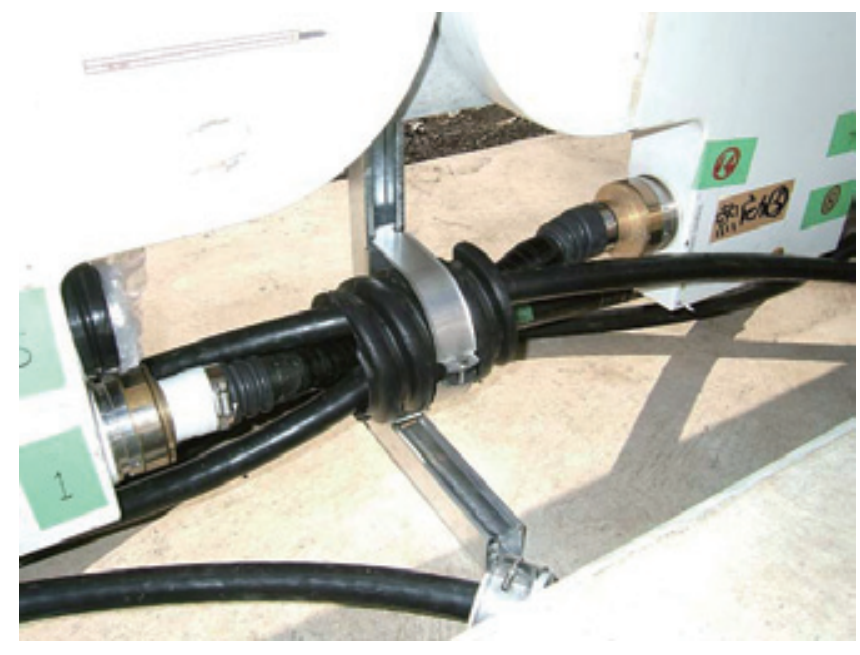

(a) Bundled cable fastener

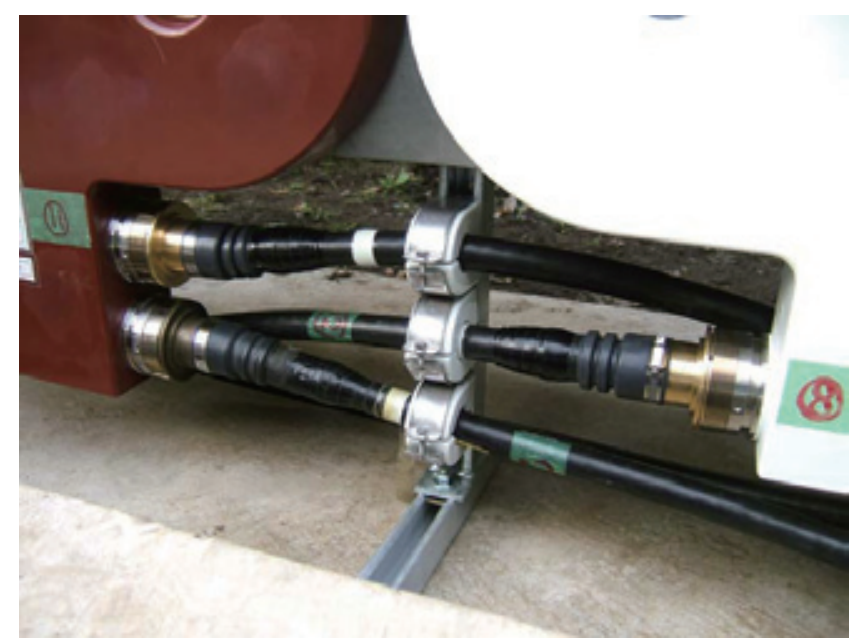

(b) Vertical individual cable fasteners

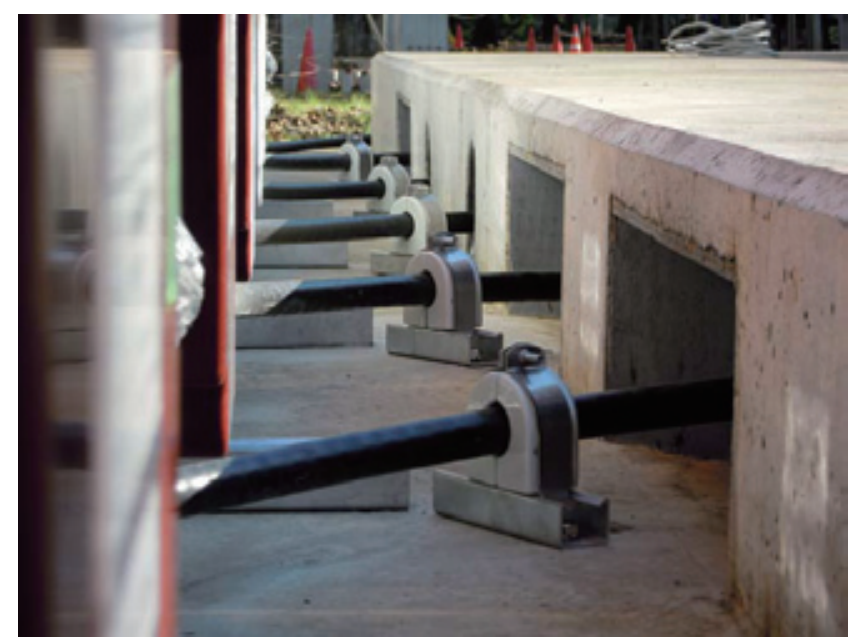

(c) Null-flux line floor fasteners

Fig. 18 Pictures of cables fasteners

verified and confirmation was obtained of their ability to fix the cables in each selected location.

Furthermore the materials used to make these fasten- ings comprise components already commercially available in the electrical industry, can be easily adapted for this application and are low cost.

\subsection{Verification points used to assess practical ap- plicability}

The results of investigations to assess the practical applicability of the above are summarized as follows:

(1) Null-flux duct line opening

As illustrated in Fig. 19, various sizes of duct openings were tried in order to improve ease of work and reduce the bending radius of cables. However, results demonstrated that even the bell-mouth opening duct was sufficient to maintain proper working conditions. On examination of the cable bending angle, it transpired that the duct opening had almost no influence on the bending angle. However, as described under point (2), the internal FEP tube diameter also plays a role when drawing the cable from the duct mouth, therefore in the case of small diameter tubing, it would be necessary to examine the bending angle in more detail.

(2) Null-flux duct line

As shown in Fig. 20, a ribbed FEP tube was used with an external diameter of $160 \mathrm{~mm}$ and internal diameter of $125 \mathrm{~mm}$. (Usually, FRP straight tubes were used (only partially ribbed).) Resistance using this type of duct was high, making work difficult and requiring use of force to feed the cables. For this trial, the material used allowed better

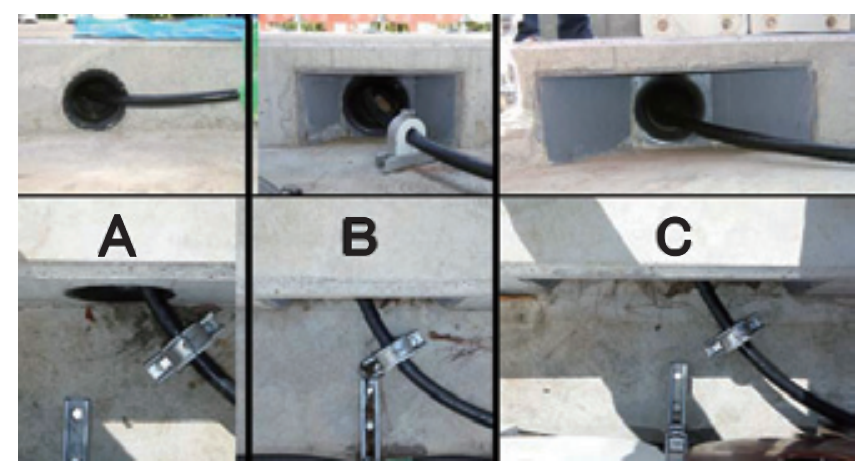

Fig. 19 Null-flux duct line opening with laid cable

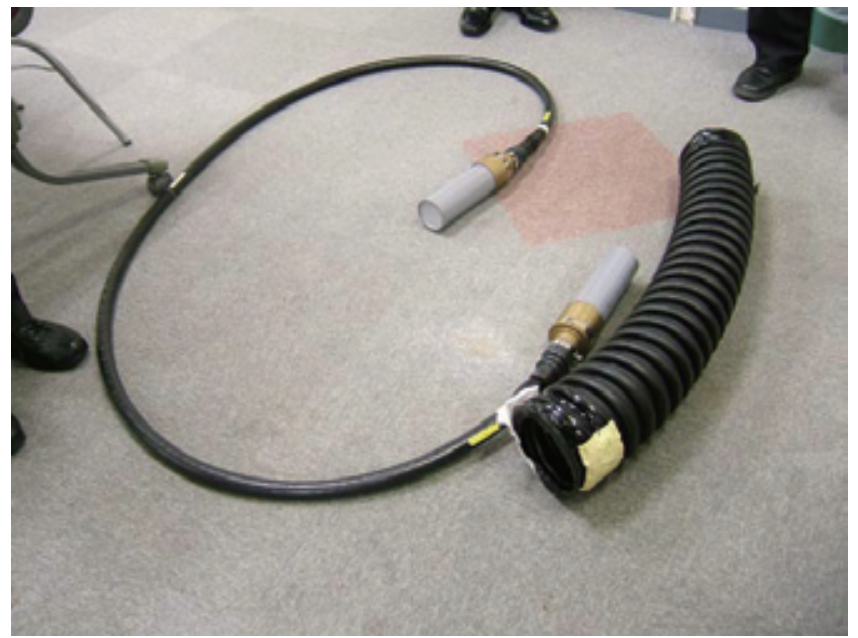

Fig. 20 Null-flux cable and FEP tube 


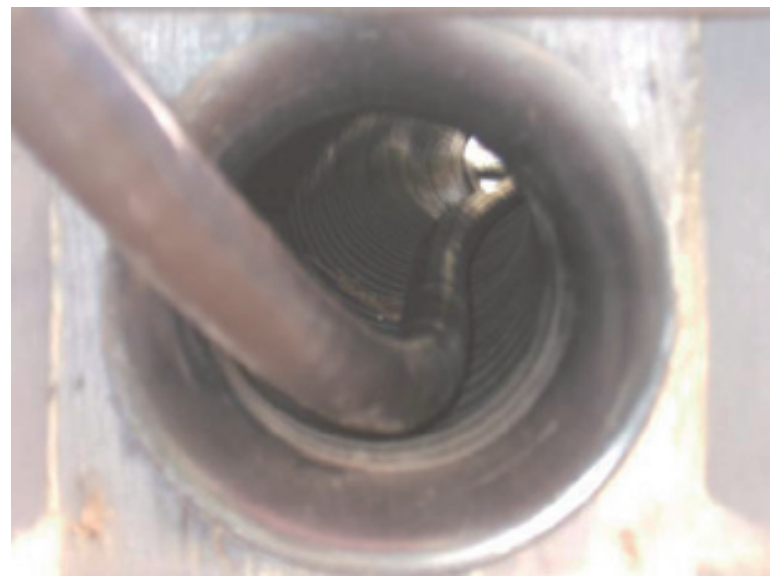

Fig. 21 Null-flux cable laying

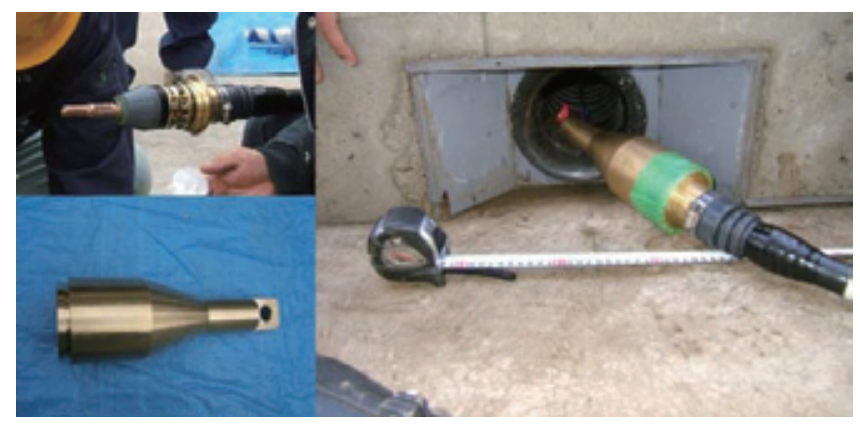

Fig. 22 A protective terminal cover and the cover in use

slip and had a ribbed surface, reducing the contact with the cable surface and therefore reducing resistance, making work demonstrably easier. Figure 21 shows the actual application of this approach. Use of ribbed FEP tubing can improve ease of work generally, and not only for the PLG method.

(3) Jig for pulling connection cables

In order to offer better protection to the connectors and facilitate work in pulling null-flux cables, as illustrated in Fig. 22 a special jig for pulling connector cables was designed and made. The same approach, aiming for a lower number of parts and easier application by adopting common work methods, used for the connector parts was applied for the coil connector fitting. The terminals were pierced with a hole, and 'messengers' such as wires were laid in place to facilitate the task of pulling later on. This technique proved to be very effective in practice.

\section{Conclusions}

Trials were performed on a model guideway wall to gain insight about cable laying order and methods used in PLG ground coils systems, in order to evaluate cable routing practicability. The results are summarized as follows;

(1) Confirmation was obtained of the required length of cable, the laying order and cable laying method.

(2) It was also demonstrated that cables can be laid on a beam-type guideway without the need for any major structural modification.

(3) It was proved that FEP tubing with a $\varphi=125 \mathrm{~mm}$ was suitably practical to be applied.

(4) It was confirmed that a bell-mouth null-flux duct opening was sufficiently practical for construction purposes without producing excessive bending, signifying that the trumpet-mouth openings were not necessary.

(5) During cable laying, protective metal fittings were effective in helping connections and the layout of cables.

(6) Cables could be fastened into place with cleats and other fastening materials, furthermore, the approximate suitable positions for these fastenings were verified.

(7) After the present evaluations, it was confirmed that the PLG method could be applied to existing guideways without major structural modification.

\section{Acknowledgments:}

This study was subsidized by the Japanese Ministry of Land, Infrastructure, Transport and Tourism.

\section{References}

[1] Murai, T., "Characteristics of Linear Synchronous Motor Combining Propulsion, Levitation and Guidance," Institute of Electrical Engineers of Japan article magazine, Vol. 114-D, No.7/8 pp.746-747, 1994.

[2] Takahashi, N., and Suzuki, M., and Aiba, M., "Construction-related Inspection of Cable Wiring of Ground Coil Type of PLG," presented at the Japan Society of Civil Engineers 2011 Annual Meeting, Matsuyama, Japan, September 22-27, 2011, Paper pp.307-308. 